\title{
Optimizing Macronutrients in People with Diabetes
}

\author{
Lovely Gupta ${ }^{1}$ Priti Rishi Lal ${ }^{1}$ Deepak Khandelwal ${ }^{2}$ \\ ${ }^{1}$ Department of Food and Nutrition, Lady Irwin College, University \\ of Delhi, New Delhi, India \\ 2Department of Endocrinology, Maharaja Agrasen Hospital, New \\ Delhi, India \\ J Soc Health Diab 2018;6:65-71.
}

\begin{abstract}
Address for correspondence Deepak Khandelwal, MD, DM, Department of Endocrinology, Maharaja Agrasen Hospital, Punjabi Bagh, New Delhi 110026, India (e-mail: khandelwalaiims@gmail.com).
\end{abstract}
Abstract
Keywords
- nutritional recommendations
- medical nutrition therapy
- macronutrients
- carbohydrates
- fats
- proteins
- nutritional requirements
- blood glucose concentrations
- insulin dose adjustments
- glycemic control

Diverse dietary practices and nutritional counseling strategies are followed in the management of diabetes and its comorbidities. The dietary approaches practiced in India make use of calorie and nutrient counting to ensure patient-centered nutrition therapy in diabetes management. Macronutrient modulation is a central pillar of patient-centered medical nutrition therapy (MNT). Carbohydrates (CHO) are considered as the predominant macronutrient affecting postprandial blood glucose levels. The insulin-to- $\mathrm{CHO}$ ratio is used for calculating mealtime insulin doses among patients on insulin regimen. The aim of this article is to highlight challenges faced in planning MNT, modifying recommended dietary allowances for persons with diabetes, and suggesting solutions to overcome these. It also aims to understand the requirement of individual macronutrients and their impact on glycemia as well as insulin dose adjustment.

\section{Introduction}

According to the World Health Organization (WHO), the incidence of diabetes is increasing worldwide. ${ }^{1}$ Medical nutrition therapy (MNT) was introduced to guide a systematic and evidence-based approach to the management of diabetes through dietary guidelines, lifestyle management, and medical treatment. ${ }^{2}$ In India, its effectiveness has been limited by multiple logistic and system-related challenges. ${ }^{3,4}$ Nutrition therapy is preferably provided by a registered dietitian who is familiar with the components of diabetes-related nutrition management. ${ }^{3,5,6}$

\section{Aims of Medical Nutrition Therapy}

The American Diabetes Association (ADA) aims at healthful eating patterns, emphasizing on a variety of nutrient dense foods in appropriate portion sizes, to improve overall health to attain individualized glycemic, blood pressure, and lipid goals. General recommended goals promote hemoglobin $\mathrm{A}_{1 \mathrm{C}}$ $\left(\mathrm{HbA}_{1 \mathrm{c}}\right)<7 \%(<53 \mathrm{mmol} / \mathrm{mol})$ in most patients to reduce the incidence of microvascular disease, blood pressure $<140 / 90 \mathrm{~mm} \mathrm{Hg}$, low-density lipoprotein (LDL) cholesterol $<100 \mathrm{mg} / \mathrm{dL}$, triglycerides $<150 \mathrm{mg} / \mathrm{dL}$, and high-density lipoprotein (HDL) cholesterol $<40 \mathrm{mg} / \mathrm{dL}$ for men and HDL cholesterol $<50 \mathrm{mg} / \mathrm{dL}$ for women. $\mathrm{HbA}_{1 \mathrm{c}}<6.5 \%$ $(48 \mathrm{mmol} / \mathrm{mol}$ ) is suggested for selected individual patients without significant hypoglycemia or other adverse effects of treatment, and less stringent $A_{1 \mathrm{c}}$ goals $<8 \%(64 \mathrm{mmol} / \mathrm{mol})$ may be appropriate for patients with a history of severe hypoglycemia, limited life expectancy, advanced microvascular or macrovascular complications, extensive comorbid conditions, or long-standing diabetes. It further aims to achieve and maintain body weight goals; delay or prevent complications of diabetes; address individual nutrition needs based on personal and cultural preferences, health literacy 
and numeracy, access to healthful food choices, willingness and ability to make behavioral changes, as well as barriers to change; maintain the pleasure of eating, and provide the patients with diabetes with practical tools for day-to-day meal planning.,7

\section{Recommendations of Medical Nutrition Therapy}

Recommended dietary allowance (RDA) for macronutrients are similar among people with and without diabetes. Healthy balanced diet with energy balance; primary prevention of overweight and obesity; and adequate quality and quantity of dietary carbohydrate ( $\mathrm{CHO}$ ), protein, fat, and micronutrient intake with active lifestyle is advised for the optimum management of blood glucose levels and balancing insulin levels in the body. ${ }^{8}$

Macronutrients are planned to match nutritional needs, exercise, and medical therapy. ${ }^{9}$ Major nutrients such as CHOs, proteins, and fats should ideally be spread throughout the day, in a in $3+3$ meal pattern ( 3 major meals and 3 minor meals). ${ }^{10,11}$ This maintains consistency in blood glucose levels and minimizes glycemic variability and its resultant complications. ${ }^{11,12}$ One must also focus on the quality of individual macronutrients. ${ }^{13}$ The ADA, Indian Council of Medical Research (ICMR), and Research Society for the Study of Diabetes in India (RSSDI) recommend that the total calorie requirements depend on physical activity and nutritional status and should be provided as six small meals a day. ${ }^{7,14,15}$

\section{Carbohydrates}

Both the quantity and quality of CHO play a crucial role in the management of diabetes. The $\mathrm{CHO}$ allowance may vary from 55 to $60 \%$, depending on the severity of hyperglycemia, weight, type of drugs/insulin, activity pattern, and patient's age and sex. CHO intake of $<100 \mathrm{~g}$ may cause starvation ketosis. Carbohydrate counting (CC) is the only method that can accurately ensure a healthy insulin-to-carbohydrate ratio (ICR), when analyzed with pre- and postmeal blood glucose. . $^{3,7,14,15}$

One serving of $\mathrm{CHO}$ equals nearly 15 to $20 \mathrm{~g}$ of $\mathrm{CHO}$. The average person needs nearly three to four exchanges (45-60 g) of CHO at each meal depending on calorie needs (i.e., pregnant/nursing, ill, etc.), medication, and activity. CC motivates patients with diabetes to easily estimate the amount (grams) of $\mathrm{CHO}$ in a particular food. Furthermore, setting $\mathrm{CHO}$ counting goals for each meal allows the patient to more easily match their $\mathrm{CHO}$ intake to the appropriate mealtime insulin dose. ${ }^{16}$ Although this technique is less evidenced in India, the literature shows its potential advantages such as improved glucose control, flexibility in food choices, and simplification of meal planning.

\section{Proteins}

Protein recommendations vary little across guidelines, with most recommending 15 to $20 \%$ of total calories for patient with or without microalbuminuria. The ADA Standard of Medical Care in Diabetes 2018 states that dietary protein restriction might be considered particularly in patients whose nephropathy seems to be progressing despite optimal glucose and blood pressure control and use of angiotensin-converting enzyme (ACE) inhibitors and/or angiotensin receptor blockers (ARBs). The National Kidney Foundation recommends $0.8 \mathrm{~g}$ protein $/ \mathrm{kg}$ body weight for people with diabetes and stages 1 to 4 chronic kidney disease (CKD) as a means of reducing albuminuria and stabilizing kidney function. Once GFR (glomerular filtration rate) falls to $<25 \mathrm{~mL} / \mathrm{min} / 1.73 \mathrm{~m}^{2}$, for patients with advanced CKD, it should be restricted to 0.6 to $0.75 \mathrm{~g} / \mathrm{kg} /$ day. ${ }^{7,16,17}$

Dietary protein contributes to the treatment of obesity, by acting on the relevant metabolic targets of satiety and energy expenditure in negative energy balance, thereby preventing a weight cycling effect. ${ }^{18}$ The amino acid requirements are based on estimates of human growth and maintenance protein requirements, a tissue amino acid pattern, and the new maintenance amino acid pattern. Plant protein sources can differ from animal sources in terms of digestibility, amino acid composition, susceptibility to hydrolysis during digestion, source, effects of processing and the presence of antinutritional factors that adversely affect digestibility and safety, and the presence of phytoprotectant factors (such as phytoestrogens) that may be advantageous in mediating disease protection. ${ }^{19-21}$

High biologic value sources of protein such as meat, poultry, fish, milk products, eggs, and soy, which contain all essential amino acids, should be emphasized to make up 50 to $75 \%$ of protein consumed. ${ }^{16}$

\section{Fats}

Total dietary intake for normal weight diabetic with normal fats can be up to 15 to $25 \%$ of total calories. Overweight persons, or those with dyslipidemia, should take $15 \%$ of calorie from fat. Further saturated fatty acid (SFA), polyunsaturated fatty acid (PUFA), and monounsaturated fatty acid (MUFA) should be $<7 \%, 10 \%$, and 10 to $13 \%$ of total fat intake, respectively, in the ratio of MUFA:PUFA:SFA as 1.2:1:0.8. N6/N3 ration can be 5 to 10 with avoidance of transfat. ${ }^{14,22}$

Recommendations mention an upper limit of $300 \mathrm{mg} /$ day for cholesterol, with fiber intake of 30 to $40 \mathrm{~g} /$ day. Soluble fiber has beneficial effects on glycemic and lipid metabolism. Though insoluble fiber has no direct effects on glycemic and lipid metabolism; it helps with satiety. ${ }^{23,24}$

Alcohol can further exacerbate liver disease, neuropathy, dyslipidemia, and obesity, and can worsen blood glucose levels. Smoking and tobacco chewing are totally prohibited. ${ }^{25}$

\section{Current Macronutrient Intake Ratio in India}

Different dietary approaches using different nutritional compositions such as low-CHO, low-GI, Mediterranean, and high-protein diets have been demonstrated to be effective in improving various markers of cardiovascular risk management of diabetes in people with diabetes. ${ }^{5,26}$ The wide spectrum of dietary options has hampered the development of overarching national nutritional guidelines in India (Kalra et al). ${ }^{27}$ 
In the United States, majority of the people with diabetes report eating moderate amounts of $\mathrm{CHO}$ ( $~ 45 \%$ of total energy intake) with average American intake of 1 to $1.5 \mathrm{~g} / \mathrm{kg} /$ day of protein. ${ }^{16}$ Similarly, a study conducted among Chilean children and adolescents with type 1 diabetes mellitus (T1DM) has shown that patients had a higher-protein intake than recommended by the International Society for Pediatric and Adolescent Diabetes (ISPAD). Dietary CHO intake was rather low, and dietary fat intake was the same as the limits recommended by the ISPAD. Diabetic control was significantly correlated with protein, $\mathrm{CHOs}$, fat, and sodium intake. ${ }^{28}$

India is undergoing nutrition transition..$^{29}$ The data presented in 2015 by Bhattacharya show that from 1947 onward there is increase in the frequency of intake and quantities of low-fiber and refined $\mathrm{CHOs}$ and fats with protein intake improving only marginally. The increasing consumption of low-fiber and refined CHOs may be related to the increased risk of insulin resistance syndrome. ${ }^{30}$

The recently published STARCH (Study To Assess the dietaRy CarboHydrate content of Indian type-2 diabetes population) study (2014) reported the mean (standard deviation [SD]) percentage of total energy intake as total $\mathrm{CHO}$, complex $\mathrm{CHO}$, and simple $\mathrm{CHO}$ as $64.1 \pm 8.3$ (95\% confidence interval [CI]: 63.3-64.9), $57.0 \pm 11.0$ (95\% CI: 55.9-58.1), and $7.1 \pm$ 10.8 (95\% CI: 6.0-8.2), respectively. The mean (SD) percentage of complex $\mathrm{CHO}$ intake from total $\mathrm{CHO}$ was $89.5 \pm 15.3$ (95\% CI: 88.0-91.1). The mean (SD) total protein/fat intake per day (g) was 57.1 (74.0)/37.2 (18.6) and 57.9 (27.2)/55.3 (98.2) in T2DM and non-T2DM groups, respectively. It concluded that Indians consume larger amounts of CHOs (64.1\% of total energy) than Americans. The comparison of macronutrients by region in India revealed similar patterns of dietary consumption, that is, relatively high CHOs and low fat and protein. ${ }^{31}$

A study conducted by Parthasarathy et al in 2015 assessed the nutritional status of Indian children and adolescents with type 1 diabetes. It reported that mean intake of energy was $79 \%$ of Indian RDA, protein was 105\% RDA, but fat intakes were high (143\% RDA) among children. ${ }^{32}$ Furthermore, a review published on dietary $\mathrm{CHO}$ content in Indian diabetic patients by Sahay in 2012 has shown that with the varying dietary approaches for management of diabetes, amount of $\mathrm{CHO}$ in the diet, type of fat, and quantity and type of protein are altered to meet individual needs. The composition of the diet, metabolic effects of high-carbohydrate and low-fat diets, types of fats and CHOs, role of fiber, and the use of food substitutes should all be considered while planning MNT. ${ }^{33}$ In patients with newly diagnosed T2DM, dietary GL and CHOs were both positively correlated with body mass index (BMI) but negatively correlated with HDL-cholesterol (HDL-C) concentration $(p<0.05){ }^{34}$

\section{Impact of Macronutrients on Glycemic Control}

It is reviewed that the difference in meal composition affects blood glucose levels variably. The immediate effects of CHOrich foods on blood glucose levels are affected by a range of food factors, for example the type of carbohydrate, food form, type and amount of dietary fiber (DF), and presence of certain food components capable of interfering with the digestive and/or absorptive mechanisms. Bell et al ${ }^{35,36}$ and Paterson et $\mathrm{a}^{37}$ have shown that meals enriched in fats and proteins are evidenced to cause a prolonged blood glucose rise by 3 to 4 hours after food ingestion, and frequently, a relative insulin resistance (-Table $\mathbf{1}$ ). In the absence of $\mathrm{CHO}$, a small to moderate portion of protein (12.5-50 g protein) did not increase the blood glucose whereas addition of a large portion (75-100 g protein) caused an increase in plasma glucose similar to that produced by $20 \mathrm{~g}$ of $\mathrm{CHO}^{35-38}$

The effects of protein ingestion on the glucose and insulin response with the carefully calculated nutrient compositions have been assessed by Nuttall et al to show that protein given with glucose increase insulin secretion and reduce the plasma glucose rise in at least some type 2 diabetic persons. ${ }^{39,40}$ Another study conducted by Layman et al (2003) has shown that women in the CHO group (CHO-protein ratio of 3.5) had higher insulin responses to meals and postprandial hypoglycemia, whereas women in the protein group ( $\mathrm{CHO}$-protein ratio of 1.4) reported

Table 1 Impact of macronutrients on glycemic control and insulin requirements

Impact of macronutrients on glycemic control

- CHOs cause immediate postprandial rise in blood glucose levels possibly because when metabolized, they get broken down and convert into sugar.

- Fats are evidenced to cause a prolonged blood glucose rise possibly due to gluconeogenesis of glycerol, a direct effect of free fatty acids (FFA), effects on other hormones, and delayed gastric emptying.

- Proteins are evidenced to cause a prolonged blood glucose rise (delaying by $\sim 1.5 \mathrm{~h}$ ) and insulin requirements possibly due to alteration of hormones, which affects glucose homeostasis and conversion of amino acids to glucose by gluconeogenic pathways.

Impact of macronutrients on insulin requirements

- Food insulin index (a measure of the postprandial insulin response to foods in healthy patients) is used as a basis for determining mealtime insulin doses.

- Insulin dose for $10 \mathrm{~g}$ of $\mathrm{CHO} / 1 \mathrm{U}$ of insulin be equivalent to the insulin required for every $100 \mathrm{kcal}$ of fat/protein (i.e., $\sim 10 \mathrm{~g}$ fat and $25 \mathrm{~g}$ protein).

- Additional insulin is given as an extended bolus over 3-6 h, depending on the number of fat/protein unit (FPU).

- High-fat/protein meals require more insulin than lower-fat/protein meals with identical CHO content.

- Meal composition, combination of nutrients, accurate macronutrient counting, digestion and absorption of each nutrient, insulin production, insulin secretion, insulin absorption, glucagon release, and individualized insulin doses are other factors to consider. 
greater satiety. It is evidenced that increasing the proportion of protein to $\mathrm{CHO}$ in the diet exhibits positive effects on body composition, blood lipids, glucose homeostasis, and satiety during weight loss. ${ }^{41}$

\section{Impact of Macronutrients on Insulin Requirements}

The study conducted by Kordonouri et al (2012) emphasized that meal-related insulin dosing should be based on $\mathrm{CHO}$ plus fat/protein counting. ${ }^{42}$ The impacts of macronutrients are summarized in $\boldsymbol{-}$ Table $1{ }^{35-38}$ However, the indices discussed - Table 1 have been evidenced to result in significant postprandial hypoglycaemia. ${ }^{43-46}$

The meal composition and combination of nutrients should be assessed to study the glycemic impact, and individualized insulin doses should be planned accordingly. The food insulin index (FII) consists of a database of around 220 food items based on the glycemic response to $1,000 \mathrm{~kJ}$ (239 kcal) portions of food in nondiabetic individuals. The ADA recommends education strategies to educate the glycemic impact of protein and fat. ${ }^{47}$ The accurate $\mathrm{CC}$ technique itself to adapt in daily practice is very challenging, and introduction of fat and protein counting must be carefully considered as a part of education. It is also evidenced that the mechanism is still very complex to understand as the effects of macronutrients are different among nondiabetic people, type 1 diabetic people, and type 2 diabetic people. It is further affected by other confounding factors ( - Table 1). . $^{42,48,49}$ These factors should be considered to calculate the patient-centered meal insulin requirements..$^{50}$

\section{Challenges to Macronutrient Optimization}

There are numerous challenges of diabetes management in India related to diet, physical activity pattern, health careseeking behavior, and health care provision. ${ }^{12,51}$ The challenges are summarized in - Table 2 . Studies show various factors such as visit to dieticians, level of education, consumption of low fat/skimmed milk, and presence of family history of diabetes being associated with consumption of diabetic diet causing poor glycemic control and higher incidence of acute and chronic complications in India. ${ }^{52}$ In addition, there is lack of awareness and misconceptions about their concepts and attitudes toward diabetes, its complications, diet, exercise, drug therapy, understanding about insulin, and treatment among patients and as well as their family members. ${ }^{12,53-59}$

There is a need to enhance the availability of cost-effective and nutritious foods, especially when dining out. The importance of meal-dependent insulin dose adjustments should also be reinforced to every patient.

\section{Possible Solutions in Medical Nutrition Therapy for Patients with Diabetes}

There is a need to achieve balanced CHO-to-protein ratio, enhance protein intake economically, and reduce $\mathrm{CHO}$ content for optimizing MNT in India. The possible solutions for optimizing MNT are highlighted in - Table 2 .

\section{Balanced Carbohydrate-to-Protein Ratio}

Hence, the following steps are involved in accurate and safe strategy to optimize the role of macronutrients before prescribing and modifying any medical therapy/insulin regimen:

- Detailed and individualized dietary assessment of patient's meal pattern and meal composition: Meal assessment helps understand the consumption of amount and type of individual nutrients in the meal, whereas meal pattern helps understand the time and distribution of those nutrients in the patient's diet.

- Physiological glycemic effects of these nutrients: The physiological effects comprise the role of varying nutrients in terms of digestibility, absorption, and postprandial effects. Area under the curve (AUC) of the serial glucose measurements during meals can also be used to assess glycemic responses. Postprandial responses can be compared for maximum increase, time to peak increase and incremental area under the glucose (AUCG), and insulin (AUCI) curves for each food. .0,60,61 $^{2}$

- Insulin-to-nutrient ratio: It will help assess the dose of insulin required for varying amounts of different nutrients consumed. ${ }^{62}$

\section{How to Enhance Protein Intake Economically?}

Protein is recommended for optimizing glycemic control or improving one or more cardiovascular disease (CVD) risk measures. In individuals with diabetes, ingested protein can increase insulin response without increasing plasma glucose concentrations. Therefore, $\mathrm{CHO}$ sources high in protein should not be used to treat or prevent hypoglycemia. ${ }^{16}$ To optimize the biological utilization of proteins, it is advantageous to consume low-quality proteins fortified with essential amino acids, nutritional benefits of mixtures of complementary protein sources, and plant genetic approaches to improve the nutritive value of food. ${ }^{21}$ Proteins from pulses, soy, grams, peas, low-fat dairy, fish, and lean meats are recommended. It is further seen that food sources with high $(>95 \%)$ true fecal digestibility, for example a typical U.S. mixed diet (egg, milk, and meat), also include wheat gluten, wheat flour and soybean-protein isolate ( Table 2)..$^{16,63}$

\section{How to Reduce Carbohydrate Content?}

Distribute the recommended allowance in small frequent meals to avoid fluctuations and postprandial insulin doses. It is recommended to combine CHOs with other food groups to achieve satiety, obtain enough calories to maintain body weight, and match eating pattern and timings to achieve nutrient to insulin ratio. Include various sources of grains and millets to achieve optimum macronutrient balance ( - Table 2 ). ${ }^{16}$

\section{Conclusion}

There is no tailor-made permanent nutrition therapy for the patients with diabetes. It keeps changing with respect to patient-centered factors, challenges, and disease complications. The RDA for nutrients needs to be prescribed considering the impact of their digestion and absorption on blood glucose levels. 
Table 2 Challenges and ways to overcome in optimizing macronutrients

\begin{tabular}{|c|c|}
\hline Challenges in optimizing macronutrients & Ways to overcome \\
\hline \multicolumn{2}{|l|}{ Related to diet } \\
\hline \multicolumn{2}{|l|}{ Misconceptions about food/diet: } \\
\hline Sources and sourcing & $\begin{array}{l}\text { - Learn and understand the food sources, role and effects of macronutrients } \\
\text { - Explore economical, but adequate, food sources of protein, such as milk and } \\
\text { milk products, eggs, or soybean } \\
\text { - Food combinations such as rice combined with pulses } \\
\text { - Include a good source of fiber-containing food items } \\
\text { - Cheaper and easy-to-carry food sources/preparations such as curd and } \\
\text { paneer/egg or daal preparations using whole cereals }\end{array}$ \\
\hline Cooking styles & $\begin{array}{l}\text { - Optimum cooking practices and judicious use in recipes such as avoid over- } \\
\text { cooking of the food items, e.g., overcooking denatures protein } \\
\text { - Use methods of fermentation and germination, etc. to enhance nutritional } \\
\text { properties }\end{array}$ \\
\hline Patterns and composition & $\begin{array}{l}\text { - Food items with good proportion of amino acids such as lean meat, soy- } \\
\text { bean, quinoa } \\
\text { - Demand for easy feasibility } \\
\text { - Prefer whole grains like whole wheat, whole oats, or other whole grain; } \\
\text { e.g., use whole-grain breads for lunch or snacks } \\
\text { - Eat less starchy foods and prefer millet, or barley or quinoa } \\
\text { - Include beans/legumes for source of slowly digested carbohydrate as well } \\
\text { as a great source of lean protein }\end{array}$ \\
\hline Quantity & $\begin{array}{l}\text { - Understand and learn about the patient-centered requirements for each } \\
\text { macronutrient }\end{array}$ \\
\hline Taboos & $\begin{array}{l}\text { - Patient-centered recommendations should be planned giving due respect } \\
\text { to social or cultural beliefs and values }\end{array}$ \\
\hline \multicolumn{2}{|l|}{ Related to physical activity } \\
\hline Declining physical activity & $\begin{array}{l}\text { - Be physically active to avoid burdening body weight and glycemic levels } \\
\text { with the macronutrients }\end{array}$ \\
\hline \multicolumn{2}{|c|}{ Related to medical treatment and health care-seeking behavior } \\
\hline Lack of trained health care professionals & $\begin{array}{l}\text { Availability of trained health care professionals for adequate patient-centered } \\
\text { nutritional counseling }\end{array}$ \\
\hline $\begin{array}{l}\text { Physicians' and patients' perception of } \\
\text { macronutrients }\end{array}$ & \multirow[t]{3}{*}{ Optimum knowledge and awareness about macronutrients* } \\
\hline $\begin{array}{l}\text { Fear of hypoglycemia or weight } \\
\text { management }\end{array}$ & \\
\hline Poor adherence/follow-up to therapy & \\
\hline Affordability & Affordable accessibility of cheap sources of food items in demand \\
\hline
\end{tabular}

Matching the dietary composition with the blood glucose levels and insulin dose adjustments can help us achieve the optimum goals of nutrition therapy among people with diabetes.

\section{References}

1 World Health Organization India. Diabetes. Available at: http://www.searo.who.int/india/topics/diabetes_mellitus/en/. Accessed September 7, 2018

2 Diet in diabetes. Available at: http://www.apiindia.org/pdf/ medicine_update_2011/24_diet_in_diabetes. Accessed August 13,2018

3 Evert AB, Boucher JL, Cypress M, et al. Nutrition therapy recommendations for the management of adults with diabetes. Diabetes Care 2014;37(Suppl 1):S120-S143
4 Shimizu T, Nathan DM, Buse JB, et al. Medical management of hyperglycemia in type 2 diabetes: a consensus algorithm for the initiation and adjustment of therapy: a consensus statement of the American Diabetes Association and the European Association for the Study of Diabetes [in Japanese] Nihon Rinsho 2012;70(Suppl 3):591-601

5 Forouhi NG, Misra A, Mohan V, Taylor R, Yancy W. Dietary and nutritional approaches for prevention and management of type 2 diabetes. BMJ 2018;361:k2234

6 Myers EF, Trostler N, Varsha V, Voet H. Insights from the Diabetes in India Nutrition Guidelines Study: adopting innovations using a knowledge transfer model. Topics Clin Nutr 2017;32(1):69-86

7 American Diabetes Association. 6. Glycemic targets: standards of medical care in diabetes - 2018. Diabetes Care. 2018; 41(Supplement 1):S55-S64 
8 Ramlo-Halsted BA, Edelman SV. The natural history of type 2 diabetes. Implications for clinical practice. Prim Care 1999;26(4):771-789

9 Inzucchi SE, Bergenstal RM, Buse JB, et al. Management of hyperglycaemia in type 2 diabetes: a patient-centered approach. Position statement of the American Diabetes Association (ADA) and the European Association for the Study of Diabetes (EASD) Diabetologia 2012;55(6):1577-1596

10 Type 1 diabetes mellitus in children and adolescents in India. Clinical practice guidelines 2011. Available at: http://www. ispae.org.in/download_docs/Diabetes_guideline_for_Web.pdf. Accessed September 3, 2018.

11 Jain R, Handa A, Tiwari D, Jain P, Gupta A. Nutrition in diabetes. Journal, Indian Academy of Clinical Medicine. 2014;15(2):125-131

12 Gupta L, Khandelwal D, Singla R, Gupta P, Kalra S. Pragmatic dietary advice for diabetes during Navratris. Indian J Endocrinol Metab 2017;21(1):231-237

13 Rušavý Z, Žourek M. Composition of macronutrients in the diabetic diet [article in Czech] Vnitr Lek 2016;62(11 Suppl 4): S94-S99

14 ICMR guidelines for management of type 2 diabetes 2018. Available at: https://medibulletin.com/wp-content/ uploads/2018/05/ICMR.diabetesGuidelines.2018.pdf. Accessed September 27, 2018

15 Bajaj S. RSSDI clinical practice recommendations for the management of type 2 diabetes mellitus 2017. Int J Diabetes Dev Ctries 2018;38(1 Suppl 1):1-115

16 Gray A. Nutritional recommendations for individuals with diabetes. [Updated 2015 May 31]. In: De Groot LJ, Chrousos G, Dungan K, et al., eds. Endotext [Internet]. South Dartmouth, MA: MDText.com, Inc.; 2000. Available at: https://www.ncbi. nlm.nih.gov/books/NBK279012/

17 Rocco MV, Berns JS; National Kidney Foundation. KDOQI clinical practice guideline for diabetes and CKD: 2012 update. Am J Kidney Dis 2012;60(5):850-886

18 Westerterp-Plantenga MS, Lemmens SG, Westerterp KR. Dietary protein-its role in satiety, energetics, weight loss and health. Br J Nutr 2012;108(Suppl 2):S105-S112

19 Millward DJ. The nutritional value of plant-based diets in relation to human amino acid and protein requirements. Proc Nutr Soc 1999;58(2):249-260

20 Millward DJ, Jackson AA. Protein/energy ratios of current diets in developed and developing countries compared with a safe protein/energy ratio: implications for recommended protein and amino acid intakes. Public Health Nutr 2004;7(3):387-405

21 Friedman M. Nutritional value of proteins from different food sources. A review. J Agric Food Chem 1996;44(1):6-29

22 Gupta L, Khandelwal D. Pragmatic selection of cooking oils. J Pak Med Assoc 2017;67(6):957-958

23 Dyson PA, Twenefour D, Breen C, et al. Diabetes UK evidence-based nutrition guidelines for the prevention and management of diabetes. Diabet Med 2018;35(5):541-547

24 Gupta L, Khandelwal D, Kalra S. Increasing fibre in South Asian Diets. J Pak Med Assoc 2018;68(7):1135-1136

25 ICMR issues new guidelines for type 2 diabetes management as patient numbers touch 72.9 million. Available at: http:// www.pharmabiz.com/NewsDetails.aspx?aid=108719\&sid=1. Accessed May 8, 2018

26 Ajala O, English P, Pinkney J. Systematic review and meta-analysis of different dietary approaches to the management of type 2 diabetes. Am J Clin Nutr 2013;97(3):505-516

27 Kalra S, Das AK, Raghupathy P, et al. Current indicators of nutritional care in children with type 1 diabetes in India: do we need a national nutritional guideline? Indian J Endocrinol Metab 2017;21(5):670-678

28 Mosso C, Halabi V, Ortiz T, Hodgson MI. Dietary intake, body composition, and physical activity among young patients with type 1 diabetes mellitus. J Pediatr Endocrinol Metab 2015;28(7-8):895-902

29 Shetty PS. Nutrition transition in India. Public health nutrition. 2002;5(1a):175-182

30 Bhattacharya M. A historical exploration of Indian diets and a possible link to insulin resistance syndrome. Appetite 2015;95:421-454

31 Joshi SR, Bhansali A, Bajaj S, et al. Results from a dietary survey in an Indian T2DM population: a STARCH study. BMJ Open 2014;4(10):e005138

32 Parthasarathy LS, Chiplonkar SA, Khadilkar AV, Khadilkar VV. Dietary modifications to improve micronutrient status of Indian children and adolescents with type 1 diabetes. Asia Pac J Clin Nutr 2015;24(1):73-82

33 Sahay BK. Dietary carbohydrate content in Indian diabetic patients. Med Update 2012;22:235:239

34 Lin X, Chen C, Lin D, et al. Dietary glycemic load and metabolic status in newly diagnosed type 2 diabetes in southeastern China. Asia Pac J Clin Nutr 2018;27(2):375-382

35 Bell KJ, Smart CE, Steil GM, Brand-Miller JC, King B, Wolpert HA. Impact of fat, protein, and glycemic index on postprandial glucose control in type 1 diabetes: implications for intensive diabetes management in the continuous glucose monitoring era. Diabetes Care 2015;38(6):1008-1015

36 Bell KJ, Gray R, Munns D, et al. Estimating insulin demand for protein-containing foods using the food insulin index. Eur J Clin Nutr 2014;68(9):1055-1059

37 Paterson MA, Smart CE, Lopez PE, et al. Influence of dietary protein on postprandial blood glucose levels in individuals with type 1 diabetes mellitus using intensive insulin therapy. Diabet Med 2016;33(5):592-598

38 Wolpert HA, Atakov-Castillo A, Smith SA, Steil GM. Dietary fat acutely increases glucose concentrations and insulin requirements in patients with type 1 diabetes: implications for carbohydrate-based bolus dose calculation and intensive diabetes management. Diabetes Care 2013;36(4):810-816

39 Nuttall FQ, Mooradian AD, Gannon MC, Billington C, Krezowski P. Effect of protein ingestion on the glucose and insulin response to a standardized oral glucose load. Diabetes Care 1984;7(5):465-470

40 Nuttall FQ, Gannon MC. Plasma glucose and insulin response to macronutrients in nondiabetic and NIDDM subjects. Diabetes Care 1991;14(9):824-838

41 Layman DK, Boileau RA, Erickson DJ, et al. A reduced ratio of dietary carbohydrate to protein improves body composition and blood lipid profiles during weight loss in adult women. J Nutr 2003;133(2):411-417

42 Kordonouri O, Hartmann R, Remus K, Bläsig S, Sadeghian E, Danne T. Benefit of supplementary fat plus protein counting as compared with conventional carbohydrate counting for insulin bolus calculation in children with pump therapy. Pediatr Diabetes 2012;13(7):540-544

43 Pańkowska E, Błazik M, Groele L. Does the fat-protein meal increase postprandial glucose level in type 1 diabetes patients on insulin pump: the conclusion of a randomized study. Diabetes Technol Ther 2012;14(1):16-22

44 Bao J, Gilbertson HR, Gray R, et al. Improving the estimation of mealtime insulin dose in adults with type 1 diabetes: the Normal Insulin Demand for Dose Adjustment (NIDDA) study. Diabetes Care 2011;34(10):2146-2151

45 Pankowska E, Kordonouri O. The complex food counting system in managing children and young people with type 1 diabetes. Diabetes Care for Children and Young People 2013;2:68-70

46 Hibbert-Jones E. Fat and protein counting in type 1 diabetes. Practical Diabetes. 2016 Sep;33(7):243-7.

47 Herman WH. Approaches to glycemic treatment sec. 7: in standards of medical care in diabetes. Diabetes Care 2015;38(10):e175 
48 Garden L, Paterson K. Macronutrients and type 1 diabetes [internet]. 2014 Oct 29; Diapedia 8105345813 rev. no. 6. Available at: https://www.diapedia.org/8105345813/rev/6

49 Tascini G, Berioli MG, Cerquiglini L, et al. Carbohydrate counting in children and adolescents with type 1 diabetes. Nutrients 2018;10(1):109

50 Krebs JD, Arahill J, Cresswell P, Weatherall M, Parry-Strong A. The effect of additional mealtime insulin bolus using an insulin-to-protein ratio compared to usual carbohydrate counting on postprandial glucose in those with type 1 diabetes who usually follow a carbohydrate-restricted diet: a randomized cross-over trial. Diabetes Obes Metab 2018;20(10):2486-2489

51 Chan JC, Gagliardino JJ, Baik SH, et al; IDMPS Investigators. Multifaceted determinants for achieving glycemic control: the International Diabetes Management Practice Study (IDMPS) Diabetes Care 2009;32(2):227-233

52 Patel M, Patel IM, Patel YM, Rathi SK. Factors associated with consumption of diabetic diet among type 2 diabetic subjects from Ahmedabad, Western India. J Health Popul Nutr 2012;30(4):447-455

53 Wangnoo SK, Maji D, Das AK, et al. Barriers and solutions to diabetes management: an Indian perspective. Indian J Endocrinol Metab 2013;17(4):594-601

54 Venkataraman K, Kannan AT, Mohan V. Challenges in diabetes management with particular reference to India. Int J Diabetes Dev Ctries 2009;29(3):103-109
55 Streisand R, Monaghan M. Young children with type 1 diabetes: challenges, research, and future directions. Curr Diab Rep 2014;14(9):520

56 Kesavadev J, Sadikot SM, Saboo B, et al. Challenges in type 1 diabetes management in South East Asia: descriptive situational assessment. Indian J Endocrinol Metab 2014;18(5):600-607

57 Weinger K, Beverly EA. Barriers to achieving glycemic targets: who omits insulin and why? Diabetes Care 2010;33(2): 450-452

58 Kalra S, Joshi S, Baruah M. Medical nutrition therapy for diabetes: the challenge in India. J Med Nutr Nutraceut 2012;1(1):3-4

59 Joseph M, Gupta RD, Gangadhara P. Barriers to nutritional practices and dietary education in patients with type 1 diabetes mellitus in India. J Global Diabetes Clin Metabol 2017;6:2

60 Whelan WJ, Hollar D, Agatston A, Dodson HJ, Tahal DS. The glycemic response is a personal attribute. IUBMB Life 2010;62(8):637-641

61 Nguyen P, Dumon H, Biourge V, Pouteau E. Measurement of postprandial incremental glucose and insulin changes in healthy dogs: influence of food adaptation and length of time of blood sampling. J Nutr 1998;128(12 Suppl):2659S-2662S

62 Gupta L, Khandelwal D, Kalra S. Carbohydrate counting-1: South Asian framework. J Pak Med Assoc 2017;67(8):1296-1298

63 Hoffman JR, Falvo MJ. Protein-which is best? J Sports Sci Med 2004;3(3):118-130 